J. Dairy Sci. 92:2843-2852

doi:10.3168/jds.2008-1886

(c) American Dairy Science Association, 2009.

\title{
Feeding behavior of calves fed small or large amounts of milk
}

\author{
T. F. Borderas, ${ }^{*} † \ddagger^{1}$ A. M. B. de Passillé, $\ddagger$ and J. Rushen $\ddagger$ \\ *Animal Welfare Program, University of British Columbia, Vancouver, British Columbia, V6T 1Z4, Canada \\ †Departamento de Producción Agrícola y Animal, Universidad Autónoma Metropolitana-Xochimilco, Mexico City 04960, Mexico \\ $\ddagger$ Pacific Agri-Food Research Centre, Agriculture and Agri-Food Canada, Agassiz, British Columbia, V0M 1A0, Canada
}

\section{ABSTRACT}

Little is known about feeding behavior in grouphoused calves fed with an automated feeding system. To examine the influence of milk feeding level on feeding behavior in such a system, we fed calves either $4 \mathrm{~L}$ of milk replacer per d (LIM) or allowed ad libitum (AL) intake ( $\mathrm{n}=25$ per treatment). In a second experiment another set of calves was fed $4 \mathrm{~L}$ (low milk volume, LM) or $12 \mathrm{~L}$ (high milk volume, HM) of whole milk $(\mathrm{n}=14$ per treatment). Results were analyzed separately using a mixed model including calf, treatment, and time as factors, and feeding behavior as variables. Milk intake by $\mathrm{AL}$ or HM calves increased during the first $2 \mathrm{wk}$, reaching a maximum intake that reached a plateau during the next 4 wk. Concentrate intake was negligible during the first $14 \mathrm{~d}$, with LIM and LM calves increasing their consumption from $d 22$. Concentrate intake by AL and HM calves remained low until weaning in experiment 1 and the end of trial in experiment 2 (d 43 for both). The frequency of visits was higher in LIM and LM calves than in AL and HM calves during the first $42 \mathrm{~d}$, with most visits being unrewarded $(\sim 90 \%)$. This resulted in higher occupancy time of the feeder by LIM and LM calves. During weaning in experiment 1 (d 44 to 48), there was no difference in occupancy time between treatments. Calves in the $\mathrm{AL}$ and HM groups distributed their visits throughout the day, whereas LIM and LM calves made most visits just before the time when the next allowance of milk became available. In experiment 1, AL calves showed a greater weight gain during the first $21 \mathrm{~d}$ but LIM calves had greater gains between d 22 and 50. However, the overall average daily weight gain was higher for AL calves. In experiment 2, HM calves had a greater gain than LM calves for the first 4 wk of trial but there was no difference between treatments during the last 2 wk. There were no differences between treatments in the incidence of disease in either experiment. The duration of time spent lying down in experiment 2 was higher

Received November 10, 2008.

Accepted February 6, 2009.

${ }^{1}$ Corresponding author: borderas@interchange.ubc.ca for HM calves but only when they were older (4 to 5 wk). No differences were found between treatments at 2 wk of age. In conclusion, feeding high levels of milk or replacer improved weight gain and reduced unrewarded visits to the milk feeder, improving the efficiency of use of the milk feeders. However, it reduced concentrate intake and the advantages were less obvious after $3 \mathrm{wk}$ of age. No increased incidence of disease was found for high-fed calves (AL and HM groups). Lying time was also higher for high-fed calves but only at an older age (4 to $5 \mathrm{wk}$ ).

Key words: dairy calf, feeding behavior, automated milk feeder

\section{INTRODUCTION}

There is a growing interest in group housing of unweaned dairy calves using an automated milk feeding system (Hepola, 2003), which substantially reduces labor requirements (Kung et al., 1997) and calves' distress at regrouping (Bøe and Færevik, 2003), and allows more flexibility in feeding schedules (Hepola, 2003). However, the advantages of automated feeders may depend upon the amount of milk or replacer fed to the calves.

Conventionally, milk-fed calves in North America are fed milk or milk replacer twice a day for a total intake of 8 to $15 \%$ of BW. However, the nutritional requirements of young calves have been underestimated (Bartlett et al., 2006), and calves fed higher (Khan et al., 2007) or ad libitum (Jasper and Weary, 2002) amounts of milk or milk replacer have much better growth rates. Calves fed ad libitum spend more time resting (De Paula Vieira et al., 2008), which may further improve their energy balance because calves have greater energy expenditure when standing than when lying down (Schrama et al., 1995). Increased levels of milk feeding (up to $8 \mathrm{~L} / \mathrm{d}$ ) have been found to improve the efficiency of use of automated milk feeding systems by reducing the number of visits the calves make to the feeders (Jensen, 2006). However, we do not know how larger milk allowances affect feeder use.

Some studies report a negative effect of increased milk allowance on health of dairy calves (Quigley et 
al., 2006). However, other studies show no increase or even a decrease in illness with high milk allowances (Appleby et al., 2001; Jasper and Weary, 2002; Khan et al., 2007). In 2 experiments, we examined how the milk feeding level of preweaned calves affects their behavior at the automated feeder, their health, and their growth. We hypothesized that larger volumes of milk or milk replacer would increase calf growth, improve the efficiency of use of the feeder, and have no negative effects on calf health.

\section{MATERIALS AND METHODS}

The institutional animal care committees (monitored by the Canadian Council for Animal Care) approved all procedures described in this study.

\section{Experiment 1}

This experiment was carried at the Dairy and Swine Research and Development Centre at Sherbrooke (Quebec, Canada) from February to August 2005. Thirty-eight female and 12 male Holstein calves [BW $=45.16 \pm 6.1 \mathrm{~kg}$ (mean $\pm \mathrm{SD})]$ were separated from their mothers within the first $24 \mathrm{~h}$ of life, weighed, fed at least $4 \mathrm{~L}$ of colostrum, and allocated to individual pens $(2.15 \mathrm{~m} \times 1.7 \mathrm{~m})$ before being moved to a woodshavings-bedded group pen $(6.45 \mathrm{~m} \times 3.4 \mathrm{~m})$ at 4.62 $\pm 1.16 \mathrm{~d}$ of life. To reduce competition, calves were moved after $21 \mathrm{~d}$ to a second wood-shavings-bedded group pen $(6.45 \mathrm{~m} \times 3.4 \mathrm{~m})$ where they were kept for another 29 d. Dynamic groups were used, with calves being added as they entered the experiment and moving to a new group as they aged. Group size varied during the experiment within a range of 3 to 16 and a mean $( \pm \mathrm{SD})$ of $9.85 \pm 1.78$ calves housed in the same pen at the same time.

Calves were fed a milk replacer (Violac, Coopérative Fédérée de Québec, Montreal, Canada) distributed at a nipple-feeding station by an automated milk feeder (Lely CALM, Woodstock, Ontario, Canada). Milk replacer nutrient content was $18.5 \% \mathrm{CP}, 18 \%$ crude fat, $0.5 \%$ crude fiber, $0.75 \% \mathrm{Ca}$, and $0.65 \%$ P. Gradual weaning was begun at d 44 of trial using the weaning program included in the automated feeder. Calves did not receive further milk replacer after d 48. A $22 \% \mathrm{CP}$ starter (Goliath XLR, Coopérative Agricole des Cantons, Québec, Canada) was available ad libitum from the first day in group pens through a feeding bowl at a feeding station controlled by the automated milk feeder system. Hay was available ad libitum from the first day in hayracks ( 2 per pen) that were freshly filled twice a day $(0800$ and $1600 \mathrm{~h})$.
Calves were randomly assigned to either a limited (LIM) milk allowance $(4 \mathrm{~L} / \mathrm{d})$ or an ad libitum (AL) milk allowance $(24 \mathrm{~L} / \mathrm{d})$. In the AL group, calves could receive meals of 0.5 to $6 \mathrm{~L}$, with an accumulation of allowance at the rate of $1 \mathrm{~L} / \mathrm{h}$ (i.e., a total daily accumulation of $24 \mathrm{~L}$ ). For LIM calves, the meal size ranged from 0.5 to $2 \mathrm{~L}$. For both groups, a new allotment of milk was given at 1000 and $2300 \mathrm{~h}$.

We recorded the daily intake of milk replacer and grain as well as the number of rewarded and unrewarded visits at the milk and grain feeder. Body weight $(\mathrm{kg})$ of all calves was measured on d 1, 21, and 50 .

Daily health checks were performed by a qualified veterinarian on all calves during the whole trial. During the first $3 \mathrm{wk}$ of life, the health check included rectal temperature, cardiac and respiratory rates and sounds, presence of diarrhea (firm, soft, liquid), presence of nasal and ocular discharges (none, clear, turbid), general state of the coat and dehydration including tent test, and muzzle humidity (dry, humid, damp). During the rest of the trial (wk 4 to 7 ) calves were visually assessed for presence of diarrhea, presence of nasal and ocular discharges, general state of the coat, and muzzle humidity. All medical treatments were recorded.

\section{Experiment 2}

This experiment was carried at the Dairy Research and Education Centre at Agassiz (British Columbia, Canada) from March to August 2006. Twenty-three female and 5 male Holstein calves $[\mathrm{BW}=43.4 \pm 4.9$ $\mathrm{kg}$ (mean $\pm \mathrm{SD})$ ] were separated from their mothers within the first $24 \mathrm{~h}$ of life, weighed, fed at least $4 \mathrm{~L}$ of colostrum, and allocated to wood-shavings-bedded individual pens $(1.3 \mathrm{~m} \times 1.8 \mathrm{~m})$ before being moved to a wood-shavings-bedded group pen $(2.6 \mathrm{~m} \times 6.5 \mathrm{~m})$ at $5.19 \pm 1.27 \mathrm{~d}$ of life. Group size varied during the experiment within a range of 4 to 13 and a mean $( \pm S D)$ of $10.78 \pm 1.91$ calves housed in the same pen at the same time.

All calves were fed whole milk from an automated milk feeder (Lely CALM) equipped with a weigh scale under the feeding stall to record BW. A $21.6 \%$ CP starter (Unifeed Ltd., Chilliwack, Canada) was available ad libitum from the first day on group pens through a feeding bowl at a feeding station belonging to the automated milk feeder system. Hay was available ad libitum from the first day through hayracks, which were freshly filled twice a day (0900 and $1500 \mathrm{~h}$ ).

For the purposes of another experiment, calves were blocked for coat color and then randomly allocated to be offered either $4 \mathrm{~L}(\mathrm{n}=14$; low milk volume, $\mathbf{L M})$ or $12 \mathrm{~L}$ ( $\mathrm{n}=14$; high milk volume, $\mathbf{H M}$ ) of whole milk/d 
A
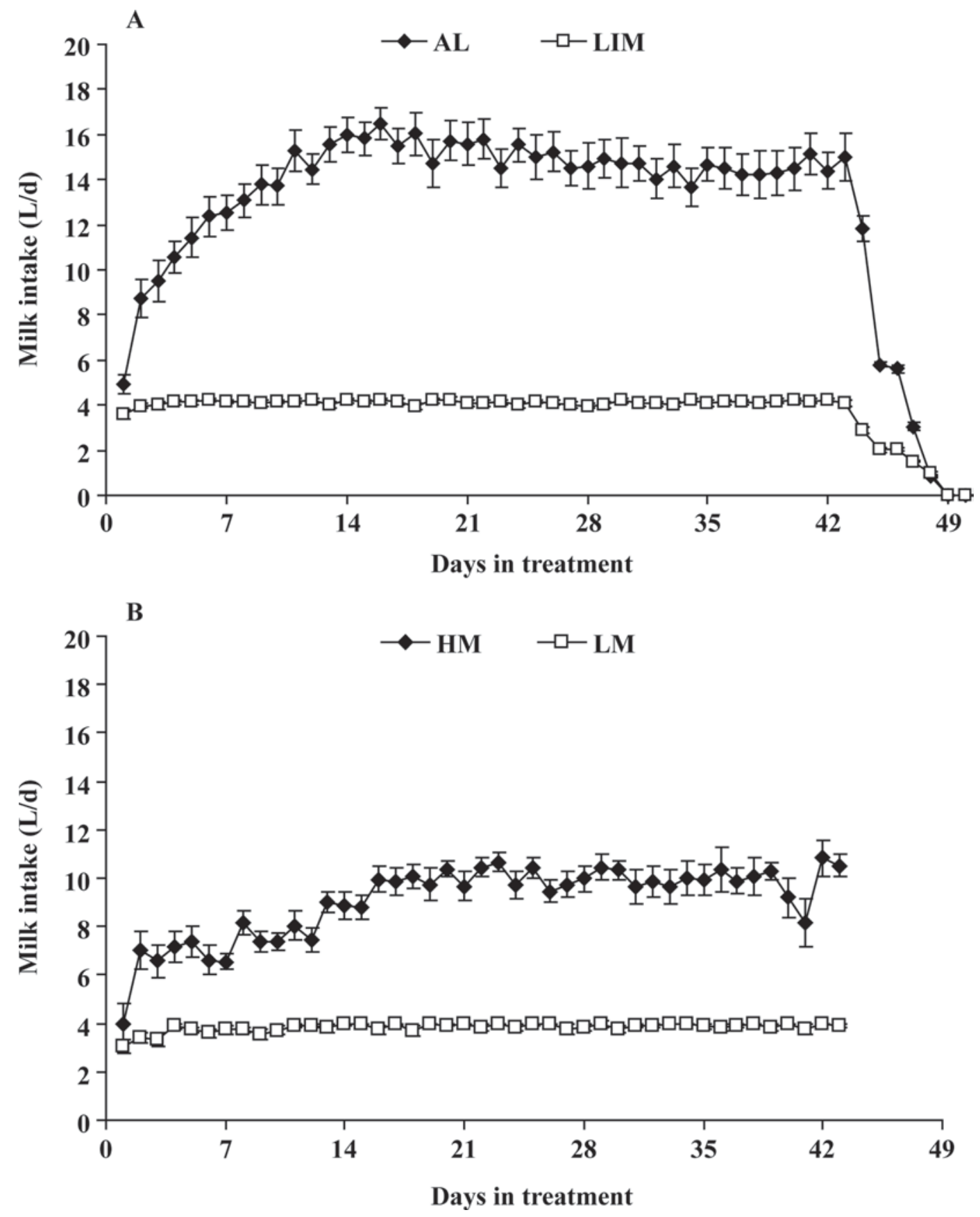

Figure 1. Daily intake (kg; mean $\pm \mathrm{SE}$ ) of milk replacer of calves fed ad libitum (AL) or limited (LIM) milk replacer in experiment 1 (A), or high (HM) and low (LM) levels of milk in experiment 2 (B). Calves in experiment 1 (A) were weaned from d 44 to 48 ; no milk replacer was offered on d 49 and 50.

(taken from the bulk tank of the farm with $\sim 150$ cows in lactation) from $\mathrm{d} 5$ to 43 of age. The HM group meal size could vary from 0.5 to $6 \mathrm{~L}$, with a distribution rate of $0.5 \mathrm{~L} / \mathrm{h}$ (i.e., maximum accumulation of $12 \mathrm{~L} / \mathrm{d}$ ). In the LM group, the meal size range was from 0.5 to $2 \mathrm{~L}$. For both groups, a new allotment of milk was given at 0900 and $1900 \mathrm{~h}$.
We recorded the daily intake of milk and grain as well as the number of rewarded and unrewarded visits to the milk and grain feeder. Body weight was recorded every day. In addition, the number of lying bouts and the total time spent lying were recorded during $7 \mathrm{~d}$ on calves in both treatments at 2 different age ranges (from 7 to $14 \mathrm{~d}$ of age and from 28 to $35 \mathrm{~d}$ of age) 


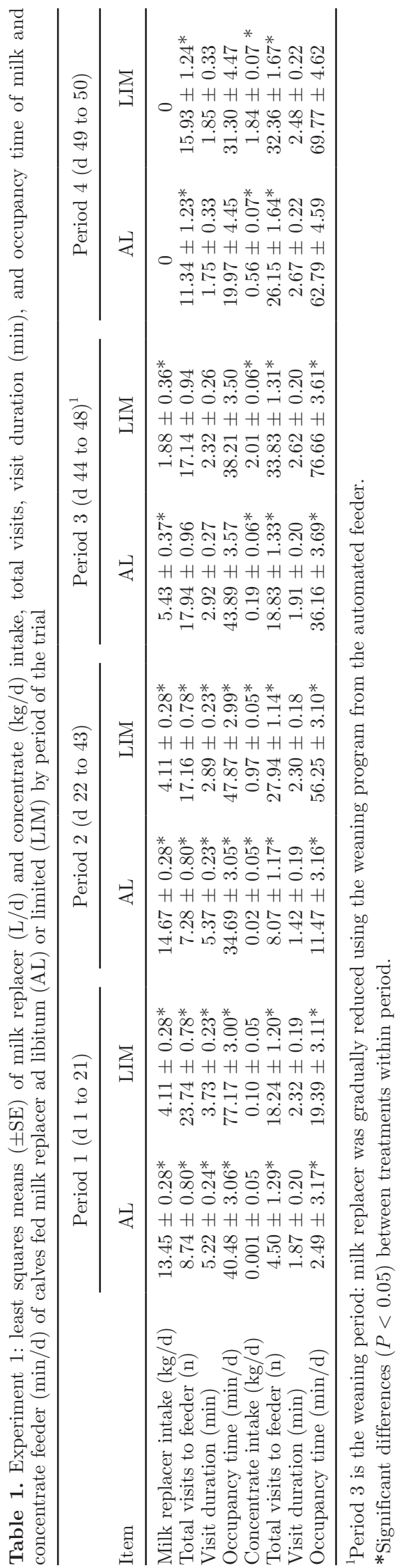

using Tinytag data loggers (Gemini Dataloggers Ltd., Chichester, UK) as described by De Paula Vieira et al. (2008). Health checks were performed daily on all calves by a qualified veterinarian. These included respiratory and cardiac rates and sounds, rectal temperature, general appearance (active, dullness), presence of diarrhea (firm, soft, or liquid feces), and presence of ocular discharges (none, clear, turbid). All medical treatments were recorded.

Boluses of neomycin and sulfametazine (Neo Sulfa-E, Vetoquinol Inc., Lavaltrie, Quebec, Canada) were used in 2 calves in experiment 1 . A kaolin-pectate suspension (Kaopectate, Pfizer Inc., Kirkland, Quebec, Canada) was used on 4 calves in experiment 1. Rehydrating solutions (Electrolytes Plus, Vetoquinol Inc., in experiment 1; Hydrafeed, EXL Laboratories, Minneapolis, MN, in experiment 2) were used for the remaining sick calves in both experiments. Medical treatments lasted an average $( \pm \mathrm{SD})$ of $2.42( \pm 0.8) \mathrm{d}$ with a range of 1 to $4 \mathrm{~d}$.

\section{Statistical Analysis}

For both experiments, the amount (L) of served milk or milk replacer and concentrate, the number of total visits (rewarded and unrewarded), and the duration (min) of each visit to the milk and concentrate feeders were automatically recorded by the feeding system. Visits were defined using the frequency distribution of natural $\log$ intervals between times when the receiver on the feeder gained or lost contact with the radio frequency ID transmitter on the calf, following the methods described by von Keyserlingk et al. (2004). Occupancy time of the feeders was calculated as the sum of the durations of all visits for each calf each day. The interval between visits was calculated as the time (min) elapsed between a visit and the subsequent one. Milk or milk replacer refusal (L) was measured by using an independent scale where a container collected the refuse discarded by the milk feeder immediately after each visit. Milk or milk replacer intake was calculated as the difference between milk served by the milk feeder and the refusal.

In experiment 1 , we analyzed the data in 4 periods: period 1 included d 1 to 21 of trial; period 2 included d 22 to 43 ; period 3 covered the period of gradual weaning ( $\mathrm{d} 44$ to $\mathrm{d} 48$ ); and period 4 covered the period after weaning (d 49 and 50). In experiment 2, we only took observations during periods 1 and 2 before weaning began. Results from both experiments were analyzed using a repeated-measures mixed model (PROC MIXED; SAS Institute, 1999) including calf as random component of the model and treatment, period of the trial, and their interaction as fixed components. Feeding behaviors (milk or milk replacer intake, concentrate 
Table 2. Experiment 2: least squares means of milk $(\mathrm{L} / \mathrm{d})$ and concentrate $(\mathrm{kg} / \mathrm{d})$ intake, total visits, visit duration and occupancy time of the milk and concentrate feeder of calves with high (HM) or low (LM) allowance of whole milk by period of the trial

\begin{tabular}{|c|c|c|c|c|}
\hline \multirow[b]{2}{*}{ Item } & \multicolumn{2}{|c|}{ Period 1 (d 1 to 21$)$} & \multicolumn{2}{|c|}{ Period 2 (d 22 to 43$)$} \\
\hline & HM & $\mathrm{LM}$ & $\mathrm{HM}$ & $\mathrm{LM}$ \\
\hline Total visits to the feeder (n) & $11.85 \pm 1.19^{*}$ & $23.05 \pm 1.19^{*}$ & $10.82 \pm 1.20^{*}$ & $19.40 \pm 1.20^{*}$ \\
\hline Visit duration (min) & $3.23 \pm 0.31$ & $2.58 \pm 0.31$ & $2.80 \pm 0.32 *$ & $1.72 \pm 0.32 *$ \\
\hline Occupancy time (min/calf per day) & $32.21 \pm 3.02^{*}$ & $53.65 \pm 3.02 *$ & $26.25 \pm 3.06$ & $30.89 \pm 3.07$ \\
\hline Concentrate intake $(\mathrm{kg})$ & $0.04 \pm 0.07$ & $0.16 \pm 0.07$ & $0.12 \pm 0.07^{*}$ & $0.66 \pm 0.07^{*}$ \\
\hline Occupancy time (min/calf per day) & $8.72 \pm 1.89^{*}$ & $22.01 \pm 1.89^{*}$ & $11.40 \pm 1.91^{*}$ & $43.61 \pm 1.91^{*}$ \\
\hline
\end{tabular}

*Significant differences $(P<0.05)$ between treatments within period.

intake, number of visits to the milk and concentrate feeders, duration of the visits, and interval between visits) were the response variables. In experiment 2 , lying behavior was also included with the frequency and duration of lying bouts as response variables.

In experiment 1 , differences between average daily weight gains were calculated with a linear model (PROC GLM) where BW at d 1 was used as a covariable. In experiment $2, \mathrm{BW}$ recorded at every visit to the feeder by the feeding station scale were sorted by calf, and the daily median was calculated as the daily BW. The median daily BW gains were used to calculate an average daily weight gain per week.

\section{RESULTS}

In both experiments, there were significant $(P<$ 0.01 ) effects of treatment, period of the trial, and their interaction for all variables, with the exception of the duration of the visits to the concentrate feeder, for which there was only a tendency $(P=0.09)$ for the effect of treatment in experiment 1 , and no effect of the interaction of treatment and period of the trial in experiment $2(P=0.43)$.

Figure 1 shows the average daily intake of milk or milk replacer by calves in experiments 1 (Figure 1A) and 2 (Figure 1B), and the mean daily intakes of milk replacer or milk for each period of the trial are shown in Tables 1 and 2, respectively. In both experiments, the calves fed large amounts of milk replacer or milk (AL and $\mathrm{HM}$ ) increased their consumption during the first $2 \mathrm{wk}$, reaching a maximum intake that was sustained during the following $4 \mathrm{wk}$. The consumption of milk replacer by calves in experiment 1 was considerably greater than the consumption of whole milk by the calves in experiment 2 . In experiment 1 , the average (mean $\pm \mathrm{SD})$ meal size was higher $(P<0.001)$ for $\mathrm{AL}$ calves $(2.68 \pm 1.07 \mathrm{~L})$ than for LIM calves $(1.72 \pm 0.42$ $\mathrm{L}$ ), whereas in experiment 2 , the average meal size did not differ $(P=0.35$; mean $\pm \mathrm{SD}: \mathrm{HM}=2.00 \pm 0.63 \mathrm{~L}$; $\mathrm{LM}=1.93 \pm 0.45 \mathrm{~L})$.

Figure 2 shows the average daily intake of concentrate by calves in experiment 1 (Figure $2 \mathrm{~A}$ ) and 2 (Figure 2B), and Tables 1 and 2 show the concentrate intake during each period of the trial. Concentrate intake for all calves was negligible during the first $14 \mathrm{~d}$. Calves in the LIM and LM groups showed a significant increase of concentrate consumption during the second period (d 22 to 43). Concentrate intake by the calves in the $\mathrm{AL}$ and HM groups remained low until weaning. In experiment 1 , concentrate intake by $\mathrm{AL}$ calves increased markedly during and after weaning but remained below that of LIM calves.

The total frequency of visits to the milk feeder was higher in LIM and LM calves than in AL and HM calves during the first $42 \mathrm{~d}$ (Tables 1 and 2). Most of the visits by low-fed calves in both experiments were unrewarded (90.6\% for LIM calves in experiment 1 and $89.07 \%$ for LM calves in experiment 2). This resulted in a higher occupancy time of the milk feeder during the first 21 $\mathrm{d}$ for LM calves in experiment 2 and during the first and second period ( $43 \mathrm{~d}$ ) for LIM calves in experiment 1 compared with their high-fed counterparts (Tables 1 and 2). During the weaning period in experiment 1 (d 44 to 48), there was no difference in occupancy time of the milk feeder between treatments $(P=0.26)$. However, there was a tendency $(P=0.07)$ for LIM calves to again spend more time in the milk feeder after weaning (Table 1).

Figure 3 shows the frequency of visits to the milk feeder in both experiments for each hour of the day. High-fed (AL and HM) distributed their visits throughout the day, whereas low-fed calves (LIM and LM) showed an increase in the number of visits around the time when milk became available to them at the feeder (1000 and $2300 \mathrm{~h}$ for experiment 1; 0900 and $1900 \mathrm{~h}$ for experiment 2). In experiment 1, LIM calves had $25.32 \%$ of their total rewarded visits between 1000 and $1200 \mathrm{~h}$ 


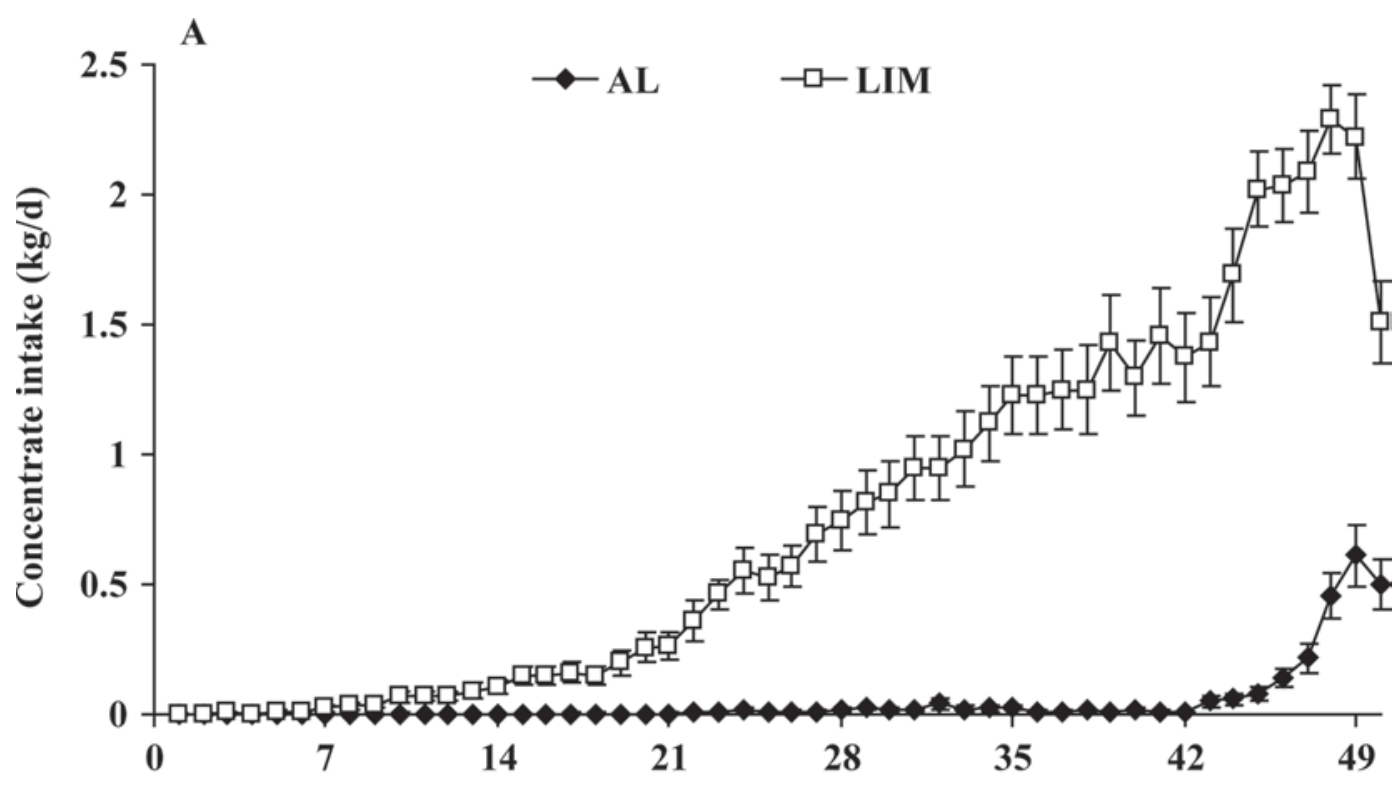

Days in treatment

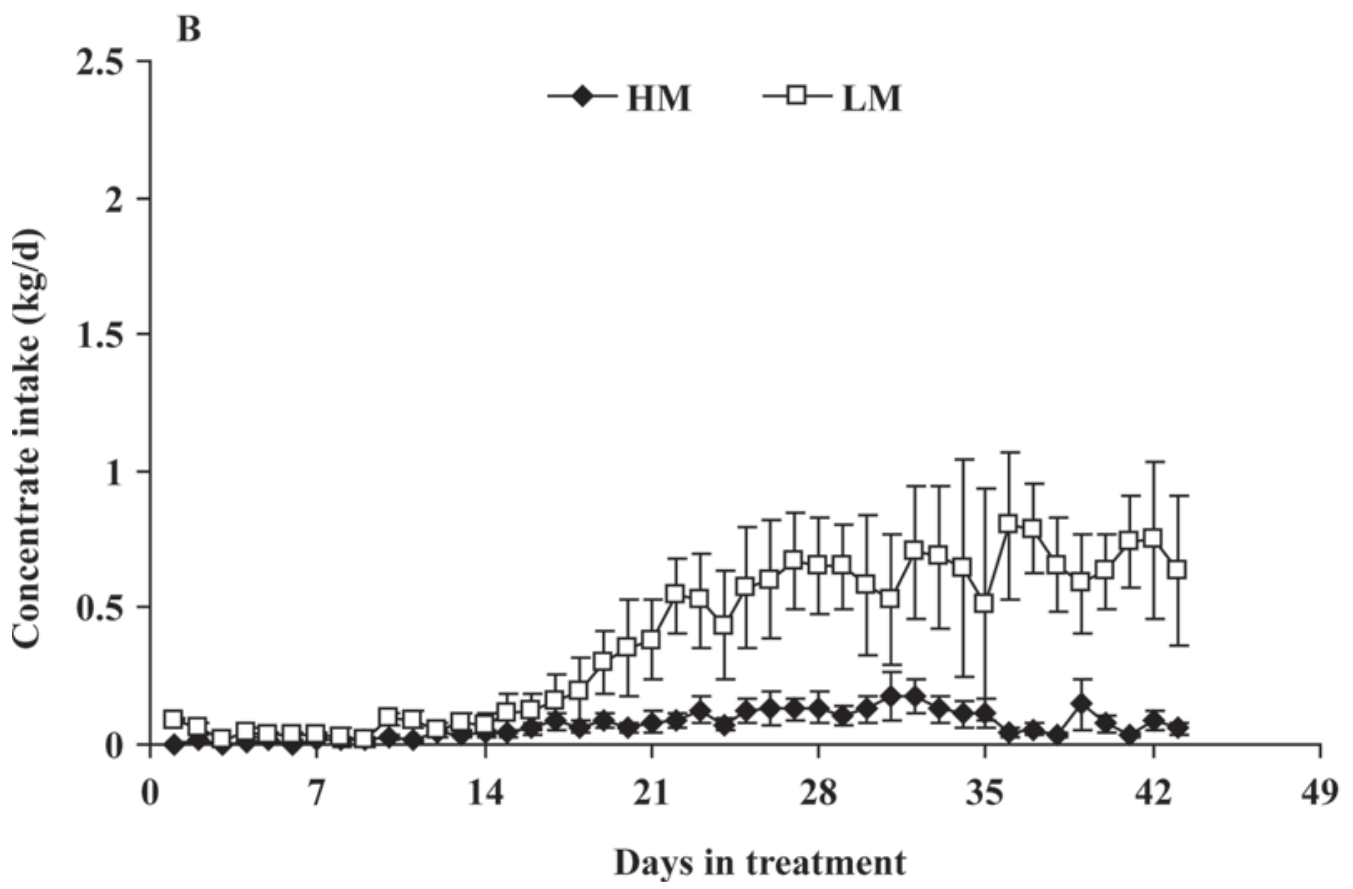

Figure 2. Daily intake ( $\mathrm{kg}$; mean $\pm \mathrm{SE}$ ) of concentrate of calves fed ad libitum (AL) or limited (LIM) milk replacer in experiment 1 (A), or high (HM) and low (LM) levels of milk in experiment 2 (B). Calves in experiment 1 (A) were weaned from d 44 to 48.

and $20.33 \%$ between 2300 and $0100 \mathrm{~h}$. In experiment 2, LM calves made $16.01 \%$ of the total rewarded visits between 0900 and $1100 \mathrm{~h}$ and $30.21 \%$ between 1900 and $2100 \mathrm{~h}$.

In both experiments, the total frequency of visits to the concentrate feeder was always higher for the LIM and LM calves compared with AL and HM calves (Tables 1 and 2) and they increased throughout both trials for all calves. The duration of these visits tended $(P$ $=0.09)$ to be higher in LIM calves compared with $\mathrm{AL}$ calves in experiment 1 (Table 1), and was always higher for LM calves compared with HM calves in experiment 2 (Table 2). Occupancy time of the concentrate feeder by LIM and LM calves was always higher than in AL and HM calves during the first 2 periods (Tables 1 and 2 , respectively). During weaning in experiment 1 (pe- 

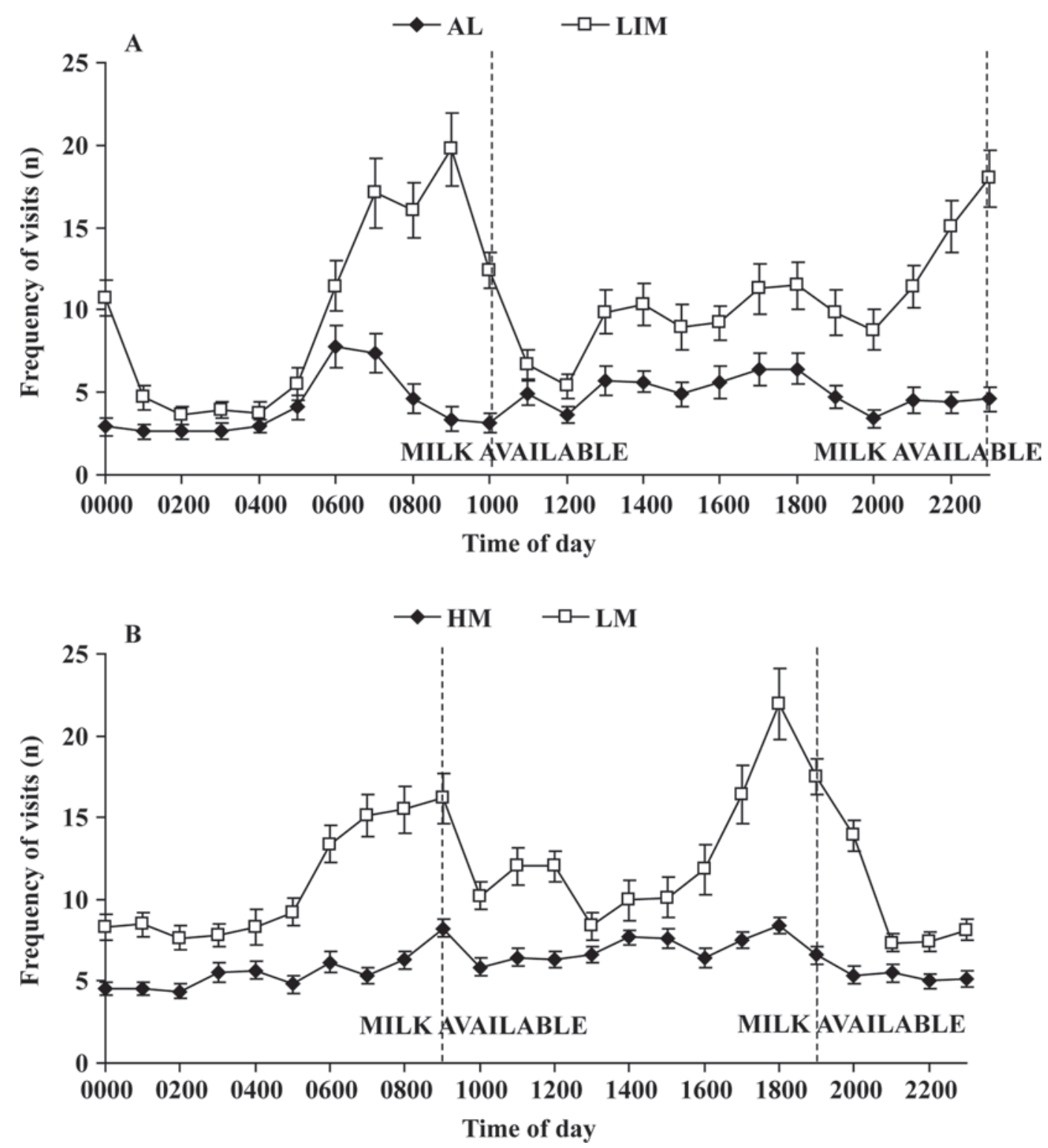

Figure 3. Mean frequency of visits at each hour of the day in experiment 1 (A) and experiment 2 (B) (mean of 10 calves/d per pen). The vertical dashed lines indicate the time that the automated milk feeder gave the calves a new allotment of milk. AL $=$ calves fed ad libitum; LIM $=$ calves fed limited milk replacer; $\mathrm{HM}=$ calves fed a high level of milk; LM = calves fed a low level of milk.

riod 3), AL calves tripled the occupancy time of the concentrate feeder compared with the previous period, but it was still significantly lower than the occupation time of the LIM calves. After weaning was completed, calves in both treatments spent similar amounts of time at the concentrate feeder $(P=0.29)$.

In experiment 1 , AL calves showed higher daily weight gain $(P<0.001)$ during the first $21 \mathrm{~d}(1.05 \pm$ $0.06 \mathrm{~kg} / \mathrm{d})$ than did LIM calves $(0.48 \pm 0.04 \mathrm{~kg} / \mathrm{d})$, but LIM calves had higher gains $(P=0.01)$ between $\mathrm{d}$ 22 and $50(0.80 \pm 0.04 \mathrm{~kg} / \mathrm{d})$ than $\mathrm{AL}$ calves $(0.62 \pm$ $0.05 \mathrm{~kg} / \mathrm{d})$. However, the overall average daily weight gain (from d 0 to 50) was higher $(P=0.03)$ for $\mathrm{AL}$ calves $(0.80 \pm 0.05 \mathrm{~kg} / \mathrm{d})$ than for LIM calves $(0.66 \pm$ $0.04 \mathrm{~kg} / \mathrm{d}$ ). In experiment 2, HM calves had a higher weight gain than LM calves for the first $4 \mathrm{wk}$ of trial (Figure 4, Table 3). There were no differences in weight gain between HM and LM calves during wk 5 and 6 in experiment 2 (Table 3 ).

There were no differences between the high- and low-fed calves in the incidence of gastrointestinal and respiratory disease in either experiment (Table 4).

Lying time in experiment 2 was affected by treatment but only when calves were older ( 4 to 5 wk). At 2 


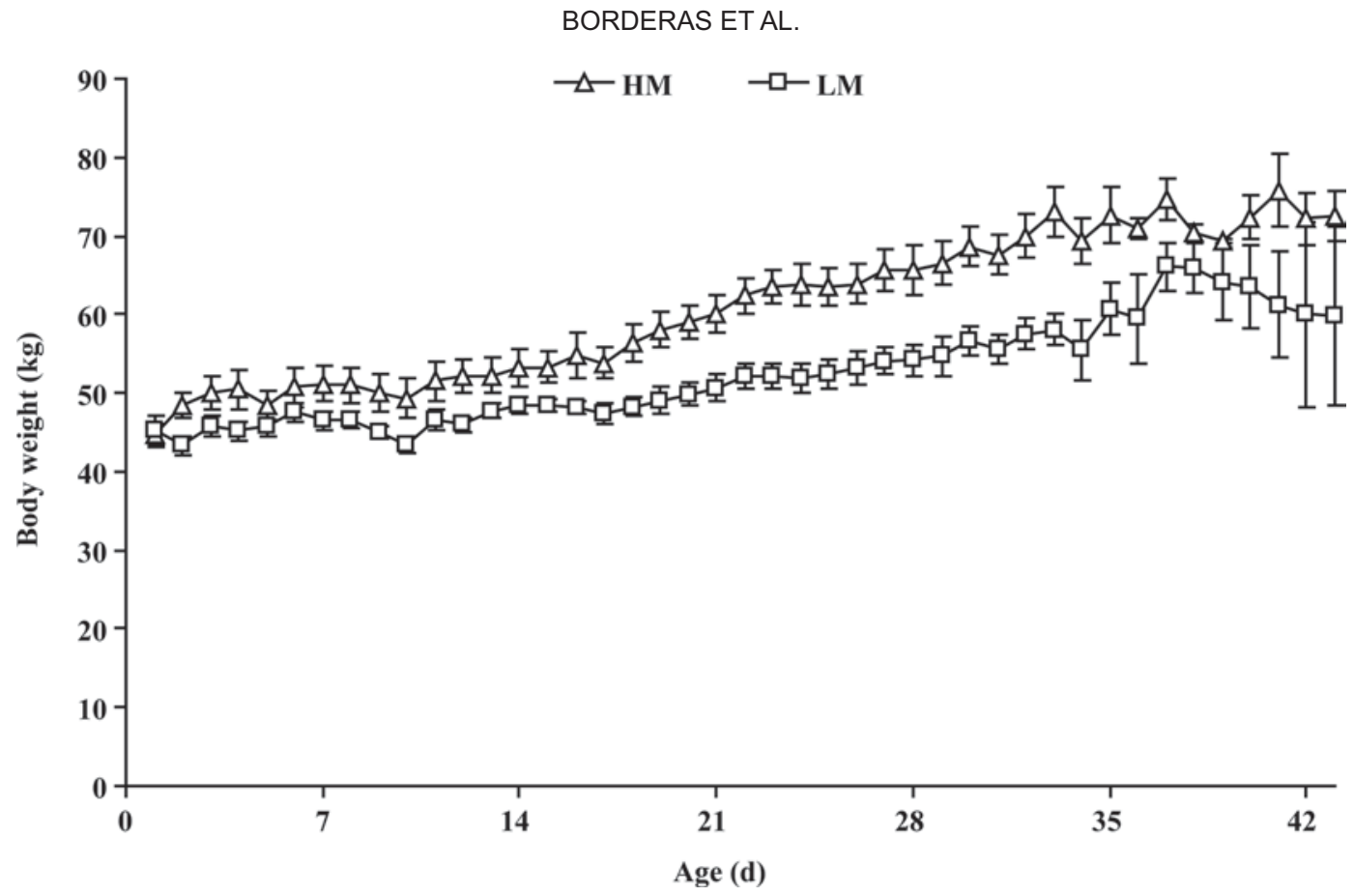

Figure 4. Body weight (kg; mean $\pm \mathrm{SE}$ ) of calves fed either high (HM) or low (LM) levels of milk in experiment 2.

wk of age, no differences were found in lying time $(\mathrm{h} / \mathrm{d})$ between HM calves $(18.7 \pm 0.14 \mathrm{~h} / \mathrm{d})$ and $\mathrm{LM}$ calves $(18.6 \pm 0.14 \mathrm{~h} / \mathrm{d})$. When calves reached 4 to 5 wk of age, both groups were spending less time lying, with HM calves lying $17.28 \pm 0.14 \mathrm{~h} / \mathrm{d}$ and LM calves lying $16.92 \pm 0.14 \mathrm{~h} / \mathrm{d})(P=0.024)$.

\section{DISCUSSION}

Results from this study confirm that dairy calves fed by an automatic feeding system can ingest large volumes of milk or milk replacer from a very young age when allowed (Appleby et al., 2001; Hammon et al., 2002; Jasper and Weary, 2002). The amounts of milk consumed in experiment 2 were similar to the amounts consumed when calves of this age were allowed to suckle from their dams (de Passillé and Rushen, 2006). The increased amount of milk replacer consumed by calves in experiment 1 compared with whole milk intake in experiment 2 most likely reflects the lower nutrient content of the milk replacer (e.g., $18.5 \%$ vs. $27 \% \mathrm{CP}$, respectively). Contrary to some findings (Quigley et al., 2006) but in agreement with other studies (Appleby et al., 2001; Jasper and Weary, 2002; Khan et al., 2007), we did not find any increase in the number of sick calves when high or ad libitum amounts of milk or milk replacer were fed.

As reported previously (Appleby et al., 2001; Chua et al., 2002; Hepola, 2003), the intake of concentrate was negligible during the first 2 to 3 wk of age, suggesting that at this age calves have difficulties compensating for reduced milk intake by increasing their concentrate intake (De Paula Vieira et al., 2008). That this results in continuing hunger of low-fed calves is shown by the large increase in the frequency of visits to the milk feeder, the majority of which were unrewarded. Calves in the $\mathrm{HM}$ or $\mathrm{AL}$ treatments also showed better $\mathrm{BW}$ gains than LM or LIM calves during this period. These results support suggestions (e.g., Appleby et al., 2001) that limiting milk intake during the first $3 \mathrm{wk}$ of life leaves calves hungry and so is detrimental to their welfare during this period.

Calves fed HM or AL levels of milk showed a small number of visits to the milk feeder that were evenly distributed throughout the day. In contrast, LIM and LM calves showed a large number of visits to the milk feeder, most of them unrewarded, as previously reported by Jensen (2006). Furthermore, rewarded visits were concentrated just before the 2 times of the day that the calves were given a new allowance of milk. This suggests that calves have a reasonably good ability to learn the timing of milk availability. This concentration of visits close to the time of renewed milk availability would most likely increase competition between the calves. The time that the milk feeder was occupied was higher for LIM or LM calves in both experiments, indicating that low levels of milk reduce the efficiency of the milk feeder.

During the second period (d 22 to 43), the low-fed calves began to eat larger amounts of concentrate. Dur- 
Table 3. Least squares means $( \pm \mathrm{SE})$ of daily $\mathrm{BW}$ gain $(\mathrm{kg} / \mathrm{d})$ per week of trial for calves fed a high (HM) or low (LM) milk allowance in experiment 2

\begin{tabular}{lcc}
\hline & \multicolumn{2}{c}{ Treatment } \\
\cline { 2 - 3 } Week & HM & LM \\
\hline 1 & $0.648 \pm 0.10^{*}$ & $0.329 \pm 0.10^{*}$ \\
2 & $0.548 \pm 0.10^{*}$ & $0.243 \pm 0.10^{*}$ \\
3 & $0.940 \pm 0.10^{*}$ & $0.405 \pm 0.10^{*}$ \\
4 & $0.876 \pm 0.09^{*}$ & $0.482 \pm 0.11^{*}$ \\
5 & $0.794 \pm 0.10$ & $0.635 \pm 0.11$ \\
6 & $0.583 \pm 0.15$ & $0.489 \pm 0.16$ \\
\hline
\end{tabular}

*Significant differences between treatments $(P<0.05)$.

ing this period, there was a reduction in the number of visits to the milk feeder and in the resulting occupancy time for LIM and LM calves. This has also been reported by Jensen (2006). Calves in the AL and HM groups also showed an increase in concentrate intake and concentrate feeder utilization during period 2 but the concentrate intake levels were still very low compared with LIM or LM calves. Thus, the advantages of a higher allowance of milk or milk replacer may be less during this period than during the first few weeks of life because the calves are more able to compensate by eating grain. In experiment 1 , the highest occupancy time of the milk feeder in $\mathrm{AL}$ calves took place during weaning (period 3). The increased time of occupancy was because of an increased number of visits by the AL calves, suggesting that the drastic reduction rate of available milk replacer and the low intake of concentrate elicited food searching similar to that observed in LIM calves during the first period.

Weight gains observed in both experiments were within the range reported in similar conditions (Appleby et al., 2001). Calves in the AL and HM groups had increased gains during the first 3 to 4 wk but this advantage disappeared when LIM and LM calves increased their concentrate intake. However, as reported by Jasper and Weary (2002), the BW of AL and HM calves was superior to that of LIM and LM calves at the end of each trial because of their initial advantage in gain as a result of their early increased milk consumption. Although concentrate intake increased dramatically at weaning in $\mathrm{AL}$ calves in experiment 1, it remained well below the intake level of LIM calves, suggesting that a better weaning strategy is needed when feeding calves high levels of milk or milk replacer.

Claims are often made that milk-feeding systems with a single teat can feed up to 45 calves. Our findings confirm previous reports (Hammon et al., 2002; Jensen, 2003; Nielsen et al., 2008) that when calves' milk allowance is limited, occupancy time increases, mainly by an increase in the frequency of unrewarded visits. Mean daily occupancy time was as high as $77 \mathrm{~min} /$ calf for LIM calves in experiment 1, and $54 \mathrm{~min} /$ calf for LM calves in experiment 2, which suggests that only a limited number of calves can be handled per feeder when milk or milk replacer is allowed at low levels. The occupancy time of AL or HM calves is similar to that reported by other authors (Appleby et al., 2001; Jensen, 2006). These results suggest that the automated feeder cannot feed more than 20 calves when milk-feeding amounts are low. However, the duration or frequency of unrewarded visits by each calf might be reduced as group size increases because of increased competition between the calves.

\section{CONCLUSIONS}

Unweaned calves will drink considerably more milk or milk replacer than is traditionally provided to them without any negative effects on their health. During the first $3 \mathrm{wk}$ of life, calves appear not to be able to adapt to low milk-feeding levels by increasing grain intake. Consequently, feeding higher amounts of milk improves weight gain. Low-fed calves make many more visits to the milk feeder, which reduces the efficiency of the automated feeding equipment and diminishes the advantages of such system by limiting the number of calves that the system can host. Because of increased hunger, restricting milk or milk replacer allowance to

Table 4. Number of calves suffering from gastrointestinal illness, respiratory illness, or both in both treatments in experiments 1 and $2^{1}$

\begin{tabular}{lccccc}
\hline & \multicolumn{2}{c}{ Experiment 1} & & \multicolumn{2}{c}{ Experiment 2 } \\
\cline { 2 - 3 } \cline { 5 - 6 } Illness & AL & LIM & & HM & LM \\
\hline Only gastrointestinal & 6 & 7 & & 3 & 2 \\
Only respiratory & 2 & 1 & & 0 & 0 \\
Gastrointestinal and respiratory & 7 & 15 & & 4 & 2 \\
Total sick & 15 & 25 & & 14 & 4 \\
Total number of calves & 25 & 74 & 14 \\
\hline
\end{tabular}

${ }^{1} \mathrm{AL}=$ ad libitum milk allowance; LIM = limited milk allowance; $\mathrm{HM}=$ high allowance of whole milk; $\mathrm{LM}=$ low allowance of whole milk. 
dairy calves during the first $3 \mathrm{wk}$ of life is likely to be detrimental to their welfare. After 3 wk of age, the ability of calves to eat grain increases and the advantages of feeding larger amounts of milk are reduced.

\section{ACKNOWLEDGMENTS}

The authors acknowledge Isabelle Blanchet, Marjolaine St-Louis, Keith Carter, and the staff at the Lennoxville dairy barn for their help, and Mairi Robertson, Nelson Dim, and the staff of the UBC Dairy Research and Education Centre in Agassiz for their support. We also thank Unifeed Ltd., Division of Agricore United, for a generous student fellowship. Funding was provided by a Discovery grant to A. M. de Passillé from the Natural Sciences and Engineering Research Council of Canada.

\section{REFERENCES}

Appleby, M. C., D. M. Weary, and B. Chua. 2001. Performance and feeding behaviour of calves on ad libitum milk from artificial teats. Appl. Anim. Behav. Sci. 74:191-201.

Bartlett, K. S., F. K. McKeith, M. J. VandeHaar, G. E. Dahl, and J. K. Drackley. 2006. Growth and body composition of dairy calves fed milk replacers containing different amounts of protein at two feeding rates. J. Anim. Sci. 84:1454-1467.

Bøe, K. E., and G. Færevik. 2003. Grouping and social preferences in calves, heifers and cows. Appl. Anim. Behav. Sci. 80:175-190.

Chua, B., E. Coenen, J. van Delen, and D. M. Weary. 2002. Effects of pair versus individual housing on the behavior and performance of dairy calves. J. Dairy Sci. 85:360-364.

de Passillé, A. M. B., and J. Rushen. 2006. Calves' behaviour during nursing is affected by feeding motivation and milk availability. Appl. Anim. Behav. Sci. 101:264-275.
De Paula Vieira, A., V. Guesdon, A. M. de Passillé, M. A. G. von Keyserlingk, and D. M. Weary. 2008. Behavioural indicators of hunger in dairy calves. Appl. Anim. Behav. Sci. 109:180-189.

Hammon, H. M., G. Schiessler, A. Nussbaum, and J. W. Blum. 2002. Feed intake patterns, growth performance, and metabolic and endocrine traits in calves fed unlimited amounts of colostrum and milk by automate, starting in the neonatal period. J. Dairy Sci. 85:3352-3362.

Hepola, H. 2003. Milk feeding systems for dairy calves in groups: Effects on feed intake, growth and health. Appl. Anim. Behav. Sci. 80:233-243.

Jasper, J., and D. M. Weary. 2002. Effects of ad libitum milk intake on dairy calves. J. Dairy Sci. 85:3054-3058.

Jensen, M. B. 2003. The effects of feeding method, milk allowance and social factors on milk feeding behaviour and cross-sucking in group housed dairy calves. Appl. Anim. Behav. Sci. 80:191-206.

Jensen, M. B. 2006. Computer-controlled milk feeding of group-housed calves: The effect of milk allowance and weaning type. J. Dairy Sci. 89:201-206.

Khan, M. A., H. J. Lee, W. S. Lee, H. S. Kim, S. B. Kim, K. S. Ki, J. K. Ha, H. G. Lee, and Y. J. Choi. 2007. Pre- and postweaning performance of Holstein female calves fed milk through step-down and conventional methods. J. Dairy Sci. 90:876-885.

Kung, L. Jr., S. Demarco, L. N. Siebenson, E. Joyner, G. F. W. Haenlein, and R. M. Morris. 1997. An evaluation of two management systems for rearing calves fed milk replacer. J. Dairy Sci. 80:2529-2533.

Nielsen, P. P., M. B. Jensen, and L. Lidfors. 2008. Milk allowance and weaning method affect the use of a computer controlled milk feeder and the development of cross-sucking in dairy calves. Appl. Anim. Behav. Sci. 109:223-237.

Quigley, J. D., T. A. Wolfe, and T. H. Elsasser. 2006. Effects of additional milk replacer feeding on calf health, growth, and selected blood metabolites in calves. J. Dairy Sci. 89:207-216.

SAS Institute. 1999. SAS User's Guide. Version 8.0. SAS Inst. Inc., Cary, NC.

Schrama, J. W., J. P. A. Roefs, J. Gorssen, M. J. W. Heetkamp, and M. W. A. Verstegen. 1995. Alteration of heat production in young calves in relation to posture. J. Anim. Sci. 73:2254-2262.

von Keyserlingk, M. A. G., L. Brusius, and D. M. Weary. 2004. Competition for teats and feeding behavior by group-housed dairy calves. J. Dairy Sci. 87:4190-4194. 